\title{
Integral upper-limit estimation method for assessment of project design changes feasibility in industrial engineering
}

\author{
Vyacheslav Pikalov ${ }^{1}$, Aleksandr Shumov ${ }^{2, *}$, and Julia Shumova ${ }^{2}$ \\ ${ }^{1}$ STC-Geotechnologies LLC, Chelyabinsk, Russian Federation \\ ${ }^{2}$ South Ural State University (NRU), Chelyabinsk, Russian Federation
}

\begin{abstract}
This paper presents the problem of project design risk managements. The empiric evidence is based on the data registered in the analytical GeoTechRemark system integrated in the STC-Geotechnology LLC. It is established that the number of expert comments is loosely connected with the feasibility of design changes. The weighted estimate method, long used as a solution for such tasks, also has a number of drawbacks, particularly the necessity for input data uniformity, which makes this method applicable for a restricted number of design fields. A proprietary methodology has been deduced to involve integral upper-limit estimation in feasibility assessment for project design changes, which is largely correlated with the actual feasibility of changes; the methodology is also available for automation, which makes it eligible for evaluating risks connected with compliance with Russian Labor law and laws regulating industrial engineering.
\end{abstract}

\section{Introduction}

According to the Urban Planning Code of the Russian Federation, design documentation is a set of documents containing materials in the form of texts and maps (diagrams) and defining architectural, functional and technological, constructional, and engineering and technical solutions for implementation of construction and reconstruction of capital facilities [1].

Running an enterprise specializing in developing design documentation is a difficult and complex task, which is preconditioned by the dynamic contemporary market. The successfulness of a design organization depends on a number of factors, one of them being the efficiency of design-related risk management.

This issue of risk evaluation the field of project management has been elaborated to a rather high degree. These problems have been studied in papers by such researches as Ansoff H.I. [2], P.A Berdyshev [3-5], V.I. Voropayev [6], Z.M. Galperin [7], P.F. Drucker [89], E.M. Korotkov [10], I.I. Mazur [11], S. Mantel [12], J. Meredith [12], N.G. Olderogge [11], N.A. Nesterova [13], M.M. Romnova [15], A.V. Serov [13], V.M. Serov [13], J. Turner [16], V.V. Trachenko [17-21], J. Frame [22], V.D. Shapiro [11], A.A. Shefov [23].

However, until now, "there have been a lot of problems in project management that require new methodology. 87 per cent of organizations that apply the project management methodology have developed their own software tools to manage specific stages of designing process; the other $13 \%$ of organizations have introduced a unified software system to manage entire sets of projects" [17]. These numbers show the overall poor level of project design activity management, including project design risk management.

\section{Main risks in construction project design}

The main risks in capital construction project design are:

1. Financial responsibility to the contractor for delay in correction of deficiencies identified in the State expert review and making changes to the design documentation as envisaged in Article 44 of Provision of March 5, 2005, No 145 "On conduction of the State expert review of design documentation and results of engineering surveying" [24];

2. Financial responsibility to the personnel and (or) supervision authorities (in case of non-compliance with the requirements of Articles 149, 152 of the Labor Code of the Russian Federation) with engagement of personnel in overtime work due to strong time restrictions for changes to design documentation [25].

Obviously, the aforementioned risks are opposite to each other as the reduced likelihood of events connected with the first risk increases the likelihood of events connected with the second risk, and vice versa. In this context, the upper-limit estimation method for assessment of design changes feasibility is crucial for managing the risks in question.

\footnotetext{
Corresponding author: a_shumov@mail.ru
} 


\section{Feasibility of changes to design documentation}

Feasibility of making changes to design documentation is a total of financial, material, and labor resources the organization needs to spend to make changes to the design documentation. Henceforward, the article studies only labor resources, although a hypothesis is made that the researches in the paper are also true for the financial and material resources of the organization. The main requirement for the deduced method is the simplicity of calculation and possibility of its automation.

\section{Number of comments in the State expert review and the feasibility of changes to design documentation}

The first logical step to assessment of feasibility of changes to design documentation was accounting the number of comments to the project design [26] (see fig. 1 and 2). The data is retrieved from the analytical GeoTechRemark system applied by the STCGeotechnology LLC. Here, the linear correlation coefficient between the feasibility of changes and the number of comments was 0.44 .

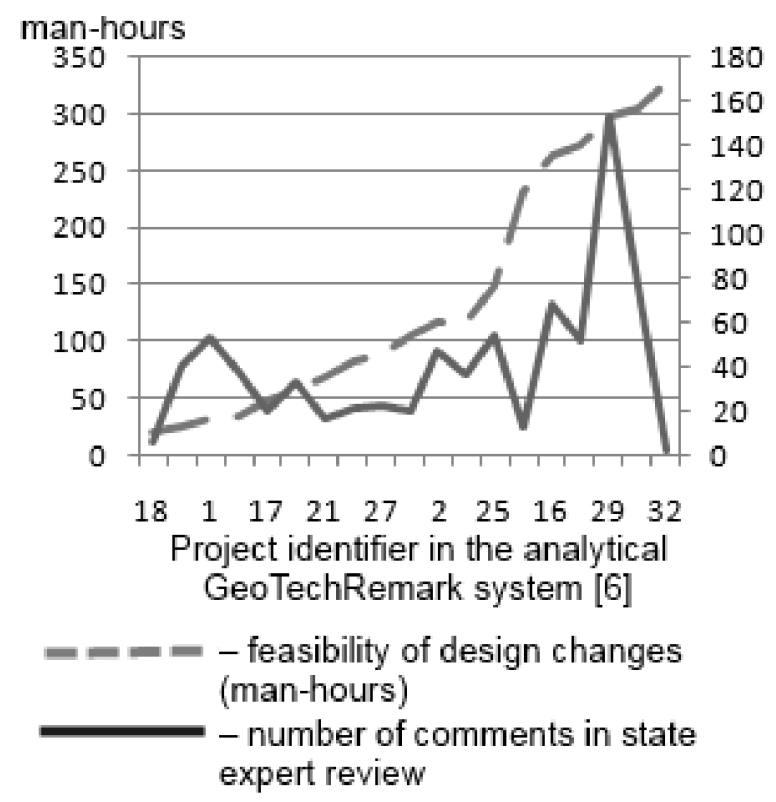

Fig. 1. Dependence of feasibility of design changes on the number of comments in the State expert review (anonymized data).

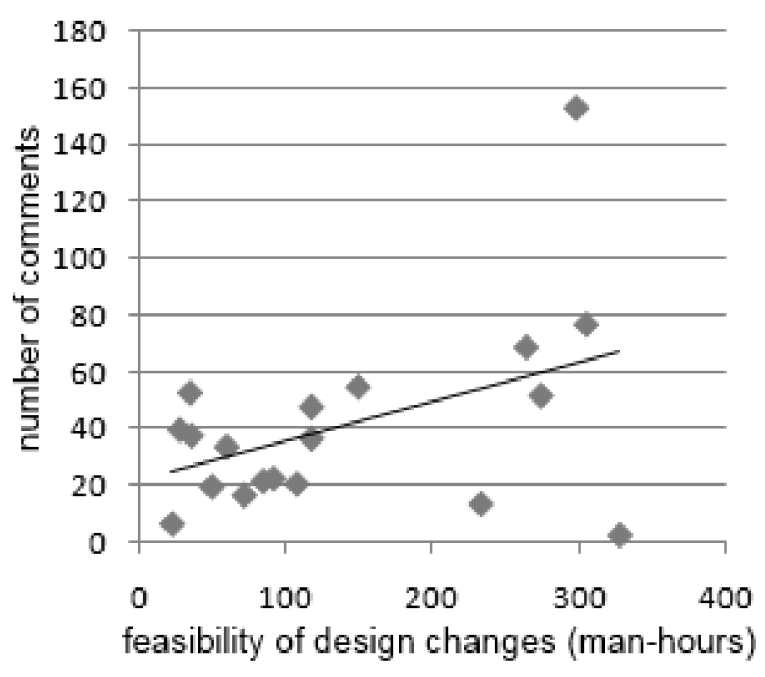

Fig. 2. Scattergram: feasibility of design changes, number of comments in State expert review.

\section{Weighted estimate of feasibility of expert comment response}

As shown in figures 1 and 2 , the feasibility of design changes is loosely connected with the number of comments, leading to the necessity to use weighted estimates and transfer from quantitative to qualitative characteristics, which is the second logical step to the solution of the stated problem. The principle is dividing all comments in categories and assigning a weight to each of them. Then, the total of all weights is calculated. Initially, the weights were calculated with the traditional for this task expert method of optimization with the objective function of highest linear correlation coefficient between the feasibility of design changes and the received estimates [27]. However, the method proved less effective when adding a new project design to the statistics or adding new comment categories to the estimate system, which makes it unacceptable for evaluation or forecasting. Note that the highest correlation coefficient between the feasibility of design changes and the weighted estimate of the feasibility of expert comment response is 0.53 (see fig. 3 and 4). 


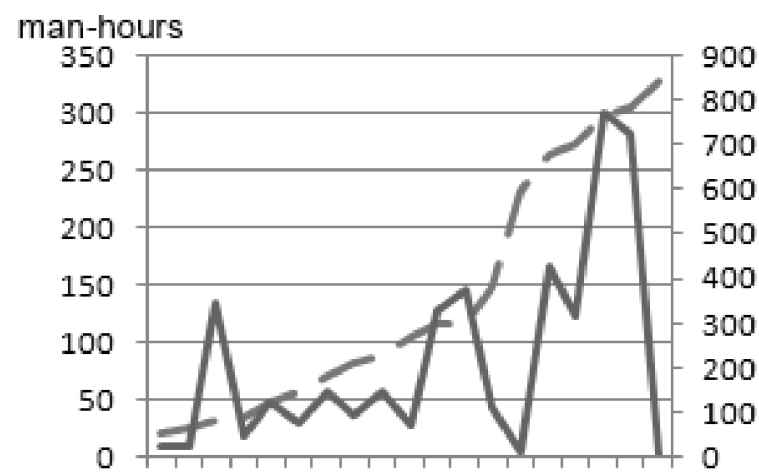

$\begin{array}{llllllllll}18 & 1 & 17 & 21 & 27 & 2 & 25 & 16 & 29 & 32\end{array}$

Project identifier in the analytical GeoTechRemark system [6]

\section{$-=-1$ feasibility of design changes (man-hours) \\ - weighted estimate of comment response (anonymized)}

Fig. 3. Dependence of feasibility of design changes on weighted estimate of feasibility of comment reponse (anonymized data).

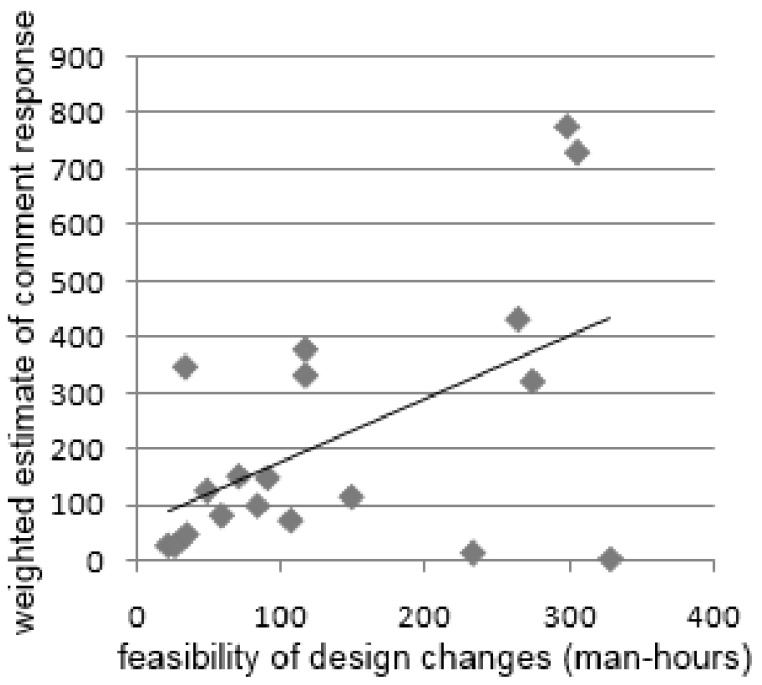

Fig. 4. Scattergram: feasibility of design changes, weighted estimate of feasibility of comment response.

Therefore, the weighted estimate method for definition of feasibility of design changes is, for a number of reasons, unstable for addition of new data such as: comments on new project design and new comment categories; i.e. it is possible to achieve certain results with this method, but it is efficient only for a restricted number of projects, which makes it acceptable only for a narrow field of application.

\section{Integral upper-limit estimation method for assessment of feasibility of design changes}

The next step in solving the specified problem was separation of feasibility of expert comment response from feasibility of design changes. As part of this separation, it is proposed to assess feasibility of comment response with the traditional expert method, and to assess feasibility of design changes with account of comment structure, design structure, and organization structure.

The upper level the design is defined by Decree 87 of the Government of the Russian Federation "On structure of design documents and requirements to their content" [28].

The next level of the design structure is formed by the structure of the organization: responsibility distribution among the departments, services and individual specialists.

The next level is conditioned by engagement of staff from outside the organization through subcontracts, fixed-term employment, and staff leasing.

Basically, this structure is not solid and can considerably vary depending on a particular organization. The best example illustrating this approach is Wolf number [29-30]. As with the Wolf number formula, the following formula (1) is proposed as solving for upper limit of integral to assess feasibility of design changes:

$\mathrm{S}=\sum_{i=1}^{n}\left(z_{i} \cdot k_{i}+5 \cdot\left(T_{i}-1\right)+10 \cdot\left(D_{i}-1\right)+20 \cdot\left(F_{i}-1\right)\right),(1)$, where:

$\mathrm{S}$ - Integral upper-limit estimate of feasibility of changes to design documentation;

$n$-number of comments;

$z_{i}$ - weight of $i$ comment;

$k_{i}$ - number of corrections (number of areas) caused by compliance with $i$ comment;

$T_{i}$ - number of volumes "affected" by compliance with $i$ comment;

$D_{i}$ - number of departments involved in compliance with $i$ comment;

$F_{i}$ - number of organizations involved in compliance with $i$ comment.

The findings are presented in fig. 5 and 6 .

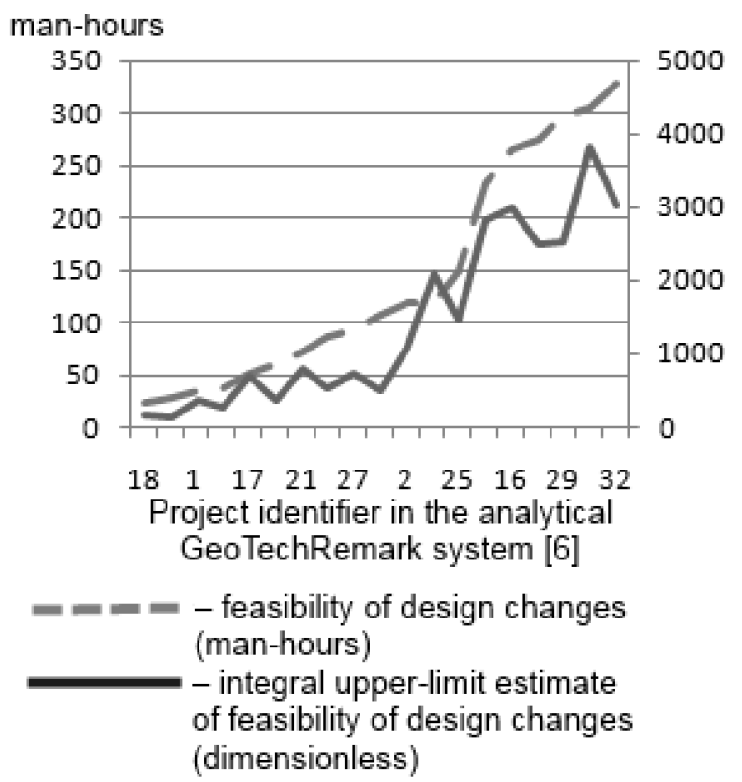

Fig. 5. Dependece of feasibility of design changes on integral upper limit estimate of design changes (anonymized data). 


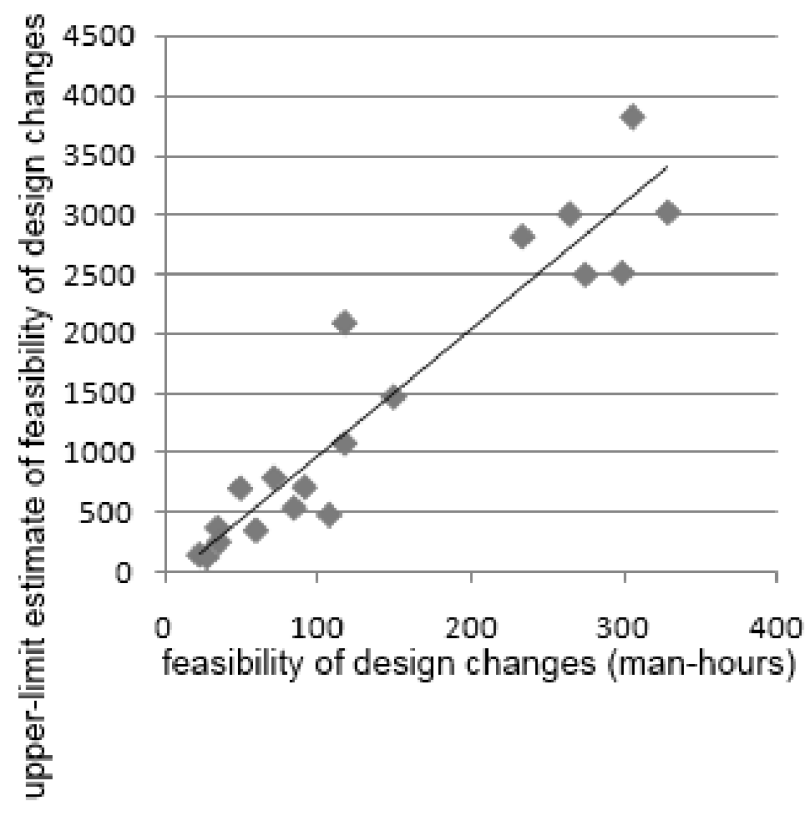

Fig. 6. Scattergram: feasibility of design changes, integral upper-limit estimate of feasibility of design changes.

\section{Conclusion (Summary)}

The deduced method of integral upper-limit of estimate of feasibility of design changes correlates well with the actual feasibility of design changes, linear correlation coefficient being equal to 0.94 (see fig. 5 and 6). Besides, the proposed method is available for automation, which makes it an acceptable method for estimation of risks connected with compliance of Russian labor law and laws regulating industrial construction design.

The work was supported by Act 211 Government of the Russian Federation, contract № 02.A03.21.0011.

\section{References}

1. The Urban Planning Code of the Russian Federation of 2004, No.190-FZ. http://www.consultant.ru

2. H.I. Ansoff, R.P. Declerk, R.L. Hayes, From Strategic Planning to Strategic Management (John Willey \& Sons, London, 1976)

3. P.A. Berdyshev, Communication management in design companies (State University of Saint Petersburg, 2009)

4. P.A. Berdyshev, News of the Russian State Pedagogical University of A.I. Herzen, 114, 327335 (2009)

5. P.A. Berdyshev, Recipes for success in projectbased management ed. By M.Martinsuo, 5-26 (2009)

6. V.I. Voropayev, Project management in Russia (Alans, Moscow, 1995)

7. Z.M. Galperina, Transportation business in Russia: research journal, 12, 108-112 (2011)
8. P.F. Drucker, Management Challenges for 21st Century (Williams, Moscow, 2007)

9. P.F. Drucker, Management for the future (Williams, Moscow, 2007)

10. E.M. Korotkov, Study of management systems (Urite publishing, Moscow, 2015)

11. I.I. Mazur, V.D. Shapiro, N.G. Oldegorre, Project Management (OMEGA-L, Moscow, 2004)

12. J. Meredith, S. Mantel, Project management (Piter $\mathrm{SPb}$, Saint Petersburg, 2014)

13. V.M. Serov, N.A. Nesterova, A.V. Serov, Organization and management in construction (Academy, Moscow, 2008)

14. M.L. Razu, Project management. Basic project management (KNORUS, Moscow, 2010)

15. M.M. Romnova, Omsk University Herald. Economics, 2, 30-34 (2011)

16. J. Rodney Turner, Handbook of project-based management (Grebennikov Publishing House, 2007)

17. V.V. Trachenko, Management of design works in a group of companies (The State University of Management, Moscow, 2008)

18. V.V. Trachenko, University Herald, 4(26) (2007)

19. V.V. Trachenko, Economics. Management. Culture, 13, 2 (2006)

20. V.V. Trachenko, Key issues of management - 2005: Materials for an international research and practice conference (2005)

21. V.V. Trachenko, Key issues of management - 2006: Materials for an international research and practice conference (2006)

22. J. Frame, Project management 2.0

23. A.A. Shefov, Multi-project management in design organizations of Russia: summary, traditions, tendencies

24. Provision of March 5, 2005, No 145 On conduction of the State expert review of design documentation and results of engineering surveying. http://www.consultant.ru

25. The Labor Code of the Russian Federation of 2001 No. 197-FZ. http://www.consultant.ru

26. S.A. Ustinova, A.V. Shumov, Efficient exploitation of mineral resources. NTC Geotechnology LLC, 10 years of experience

27. N.V. Brazovskaya, Optimization methods (PASTU, Barnaul, 2000)

28. Decree of the Government of the Russian Federation of 16.02.2008 No. 87, On structure of design documents and requirements to their content. http://www.consultant.ru

29. M. Waldmeier, Ergebnisse und Probleme der Sonnenforschung (Leipzig, 1955)

30. Y.I. Vitinsky, M. Kopetsky, G.V. Kuklin, Statistics of sunspot activity (Science, Moscow, 1986) 